\title{
Tasarım Düşüncesi İnovasyon Uygulaması: Kamu Sektöründe Vaka Çalışması
}

Öz

Bu çalışma İstanbul Büyükşehir Belediye İstanbul Gaz Dağıtım A.Ş. (İGDAŞ) kesin hesap biriminde hazırlanan dosya ve ataşmanlar hiçbir veri kaybı olmaksızın zamandan ve maliyetten tasarruf yaparak kayıt etme sisteminin tasarım düşüncesi yöntemiyle geliştirilmesiyle ilgilidir. Mevcut sistemde yılda 72 adet hak ediş dosyası için 5142 ataşman hazırlanıyor ve bu yoğun iş yükü kesin hesap birimindeki elemanların işlerini yaparken çok stresli olmaları nedeniyle birbirlerine ve özellikle de yüklenici elemanlarına oldukça sert davranmalarına yol açıyordu. Tasarım düşüncesi inovasyon sürecinin uygulanması sonucunda ataşman sayısı 5142'den 396'ya indirildi. Amacımız iş verimliliğini ve stresi etkileyen bu problemi tasarım düşüncesi inovasyon modeliyle çözerken bu sistemi tanıtmaktır. Süreçte altyapı yatırım yüklenicileri ve elemanları, danışman firma elemanları, hak edişi hazırlayan şantiye şeflikleri, müdürlüğümüzdeki şefler ve elemanlar ile diğer birimlerdeki koordinatör, şef ve elemanlarla görüşüldü. Çözümü hesap çizim formlarını yeniden düzenlemede bulunuldu. Birimin yıllık, hesap çizimleri hazırlama, kontrolü ve şantiye denetimlerinde için dökülen emeklerden toplamda 576 iş günü ve 300.000 sayfayı (\%94 altında) aşkın tasarruf sağlandl.

Anahtar Kelimeler: Tasarım düşüncesi, inovasyon, empati, tasarruf, verimlilik.

\section{Design Thinking Application: The Form Revision in Public Administration}

\begin{abstract}
This study is related to the improvement of the recording system (file preparation) with the design thinking by saving time and cost without any data loss at Istanbul Metropolitan Municipality Gas Distribution Inc.'s (IGDAŞ). In the current system, 5142 attachments are prepared per year for 72 files, and this intensive workload caused the department members to be harsh against to each other and especially to the contractors when they are stressful to do their jobs. The number of attachments has been reduced from 5142 to 396 as a result of the implementation of the design thinking as innovation process. Our aim is to introduce this innovative system by solving this problem which affects work productivity and stress. In the process, we interviewed with our staff, managers, coordinators, contractors, engineers. Our remediation that we come up is to reorganize the forms. Thanks to this new solution, time and material saving reaches 576 days and 300,000 pages (94\% down).
\end{abstract}

Keywords: Design thinking, innovation, empathy, saving, product.

\footnotetext{
* Prof. Dr., Erzincan Binali Yıldırım Üniversitesi, İ̈BF, İktisat Bölümü, mustafa.akin@erzincan.edu.tr ORCID: 0000-0002-1850-9118

I am indebted thankful to department chief Aslı Ayla Çakirgöz and Prof. Jeanne Lietka due to their support.
} 


\section{Giriş}

Bu çalışma İstanbul Büyükşehir Belediye İstanbul Gaz Dağıtım A.Ş.’nin (İGDAŞ) kesin hesap biriminde gecikmelere sebep olan dosya ve ataşmanları tasarım düşüncesi yöntemiyle geliştirilmesiyle ilgilidir. Mevcut sistemde yılda 72 adet hak ediş dosyası için 5142 ataşman hazırlanmaktadır. Bu yoğun iş yükü kesin hesap birimindeki elemanların işlerini yaparken çok stresli olmaları nedeniyle birbirlerine ve özellikle de yüklenici elemanlarına oldukça sert davranmalarına yol açmaktadır. Tasarım düşüncesi inovasyon sürecinin uygulanması sonucunda ataşman sayısı 5142'den 396'ya indirilmiştir. Amaç, iş verimliliğini ve stresi etkileyen bu problemi tasarım düşüncesi inovasyon modeliyle çözerken bu sistemi tanıtmaktır (Brown, 2008, 2009: Liedtka ve Ogilvie. 2011, Luma, 2014, Liedtka vb., 2014). Türk akademik literatüründe daha önce tasarım düşüncesi (design thinking) inovasyon sistemi üzerine bir teorik ve pratik çalışma yapılmamıştır. Bu makalede hem tasarım düşüncesinin metodolojisi hem de bir kamu idaresine uygulanma örneği analiz edilmektedir.

İGDAŞ'ta müteahhitlik hizmeti alındığında ödeme yapabilmesi için hesap kesim bölümünden onay alınması gerekmektedir. Kesin hesap bölümünde ödeme izninin verilebilmesi için birçok form doldurulmaktadır. Bu formların adına ataşman denmektedir. İş yükü bu ataşmanların şekli ve adedinden ortaya çıkmaktadır. Büyük Şehir Belediyesindeki sorunun çözümünde tasarım düşüncesi metodundan faydalanılmaktadır.

Tasarım düşüncesi bir problem-çözüm sistemi olarak kullanıcı odaklı, ekip çalışmasına dayanan, inovasyon firsatlarını yakalamaya çalışan deneme-yanılma yöntemidir (Beckman ve Barry, 2007; Brown, 2009; Kelley, 200; Lockwood, 2009; Martin, 2009). Tasarım düşüncesi sorunu anlama ve çözme sürecidir (Kelley, 2005; Kelley ve Kelley, 2014 ve Pink, 2006). Tasarım düşüncesinde inovasyon yaratıcılıktan çok bir disiplin işidir (Brown, 2008; 2009). Yaratıcılık hayal kurarak değil prosedürü takip ederek olmaktadır (Liedtka,ve Ogilivie 2011; Liedtka vd., 2014). Tasarım düşüncesi çözümü göstermede sıkı kurallarla bağlanmış bir yöntemi takip etmektedir.

Tasarım düşüncesi kullanıcıların faaliyetlerine odaklanmakta ve faaliyetleri ilerletmeye yönelik ürün sunmaktadır (Brown, 2008, 2009). Kullanıcının deneyimini ve hissini ön planda tutmaktadır. Tasarım düşüncesinde ekipler tezlerini doğrulamak için kütüphanede veya şirkette zaman geçirerek destekleyici verileri bulmaya çalışmamaktadırlar. Paydaşlarla görüşülerek sürekli olarak geri bildirimlerle “değer önerilerini” yenilemektedirler. Ürünlerin geliştirilmesi tahminlere veya dar ölçekli verilere dayalı olmak yerine kullanıcılardan ve paydaşlardan elde edilen birçok geri bildirimlerle olmaktadır.

Tasarım düşüncesinde cevaba yönelmeden önce sorunun ne olduğu tartışılmaktadır. Gerçek sorunu bulmaya çalışılmaktadır. Sorun keşfedildikten sonra çözüm önerisine hızlı geçiş yerine çözüm seçenekleri çoğaltılmaktadır (Şekil 1). Genişletilmiş çözüm listesinden daha isabetli tercihlerin yapılmasına gayret gösterilmektedir. Sorunun başında bir çözüm önermesi getirilmemektedir. Süreç boyunca çözümler bulunmaktadır. Bazıları eklenmekte ve bazıları olgunlaştırılmaktadır. Önemli olan doğru sorunu bulmak ve seçenekleri arttırmaktır. Sorunun derinine inmeden çözüm odaklı olmak tercih imkanlarını kısıtlamaktadır. Araştırmacıya ait sorun ve çözüm varsayımlarını doğrulatmak üzere çabaya girilmesine sebep olmaktadır. 
Şekil 1: Seçeneklerin Çoğaltılarak Elenmesi

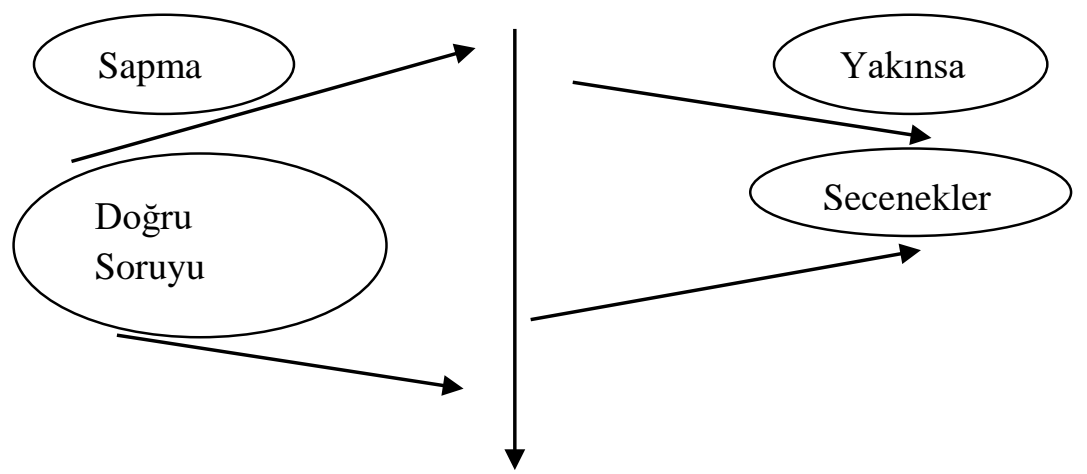

Kaynak: Beckman, ve Barry, 2013.

\section{Tasarım Düşüncesinde Sorun Çözme Metodları}

Tasarım düşüncesi sorun çözme sürecini tasarımcılardan almıştır (Beckman ve Barry, 2007; Brown, 2009; Kelley, 200; Lockwood, 2009; Martin, 2009; Hulme, 2010; Beverly, 2013). Tasarımcıların bir nesneyi yaratmak veya ilerletmek için kullandıkları araçlar ve bakış açıları süzülmüştür. Örneğin bir mobilya veya takı için kullanılan süreç bir sağlık servisinin veya organizasyon şemasının yeniden inşa edilmesi için kullanılmaya başlanmışıtır. Bir kurum tasarım düşüncesini benimsediğinde, çalışanların problemi tanımlama, firsatları keşfetme ve belirsizlikte iz bulma yöntemlerini de öğrenmekteler ((Neumeier, 2009; Parsons, 2009).

Tasarım düşüncesi tasarım yöntemlerini kullanarak inovasyon yeteneğini geliştirmek isteyen, hayal ettiğini henüz keşfedememiş ve keşfettiğini de gerçeğe dönüştürmek isteyenlere yöneliktir (Nelson ve Stolterman, 2012; Nixon, 2013).

Süreç dört aşamalı olarak ifade edilmektedir: görmek (nedir?), anlamak (peki ya!), yapmak (ne şaşırtmakta?) ve test etmektir (ne işlemekte?) (Şekil 2). Tasarım düşüncesinin araçları ve yaklaşımı kullanıcı deneyimine odaklıığı ve niteliksel araştırmayı (gözlem, mülakat, deneme-yanılma, kendisini başkasının yerine koyma) kapsamaktadır. Geleneksel iş disiplinleri operasyonel etkinlik ve bilimsel araştırma varsayımlarıyla ilerlerken, tasarım düşüncesi kullanıcı odaklı, ekip çalışması, empati esaslı ve prototiplerle ilerlemektedir (Denzin ve Lincoln, 2005).

İnovasyonu ortaya çıkartabilmek için "görmek, anlamak, yapmak, test etmek" adımları izlenmektedir (şekil 2). Görmekten amacımız insanların tecrübelerini gözlemlemek, anlamaktan zorlukları ve firsatları analiz etmek, yapmaktan gelecekteki olasılıkları görselleştirmek ve test etmekten sürekli geri bildirim elde etmektir (Liedtka ve Ogilivie, 2011; Brown, 2008, Kelley, 2002; Kelley ve Kelley,2013; Kumar, 2012). 
Şekil 2: Görmek-Anlamak-Yapmak-Test Etmek

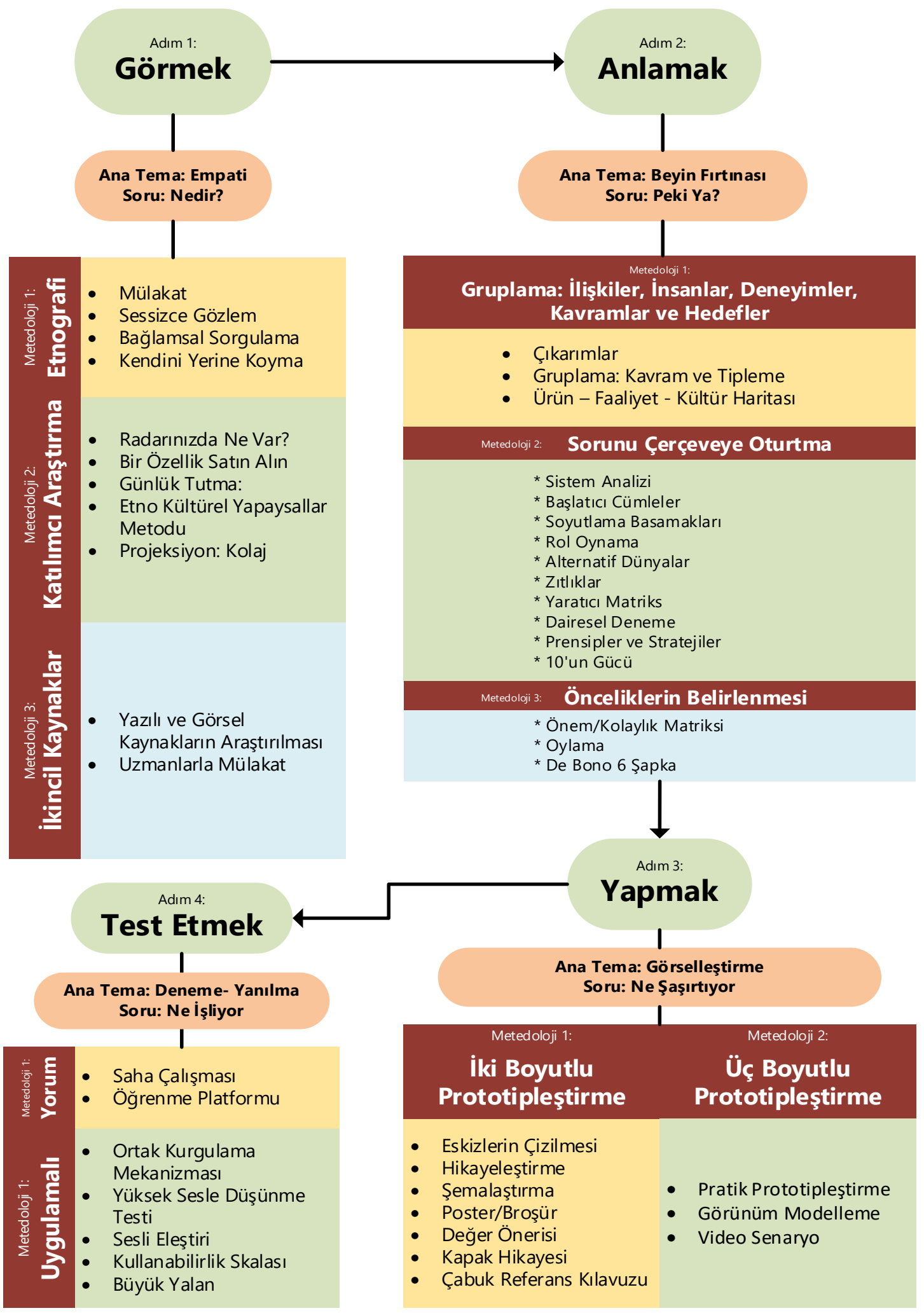

Kaynak: Luma Institute, 2014; Lietka vd., 2014; Kumar, 2012. 
İlk adım görmektir (Şekil 2). Kullanıcılarla empati kurmaya çalışılmaktadır. Konu nedir sorusu sorulmaktadır (Lietka vd., 2014; Luma Institute, 2014, 2012; Standford Design School, 2009, 2014). İlk önce paydaş haritası çıkartılmaktadır. Paydaşlar sorunu veya çözümü dolaylı ve dolaysız etkileyen tüm kişi ve kuruluşlardır. Paydaş haritasında görüşülecek kişilerin listesi oluşturulmaktadır. Bu aşamada durum, sorun, konu, insanlar, ilişkiler, hedefler, tarihsel gelişimler araştırılmaktadır. Bütün başarılı yenileşmeler konuyu doğru bir şekilde değerlendirme ile başlamaktadır. Tasarım düşüncesi ürün değil "insan” odaklıdır. Araştırmanın odağında özellikle "kullanıcılar" vardır (Klein, 2013). Karşı tarafın duygularını tanımaya yönelik empatik bilgi en temel felsefesini oluşturmaktadır. Tasarım düşüncesi metodolojisinde önemli olan doğru cevabı bulmaktan çok doğru soruyu çıkarmaktır (Pink, 2006; Lietka, ve Ogilivie, 2011).

Konuyu araştırmak için üç metodoloji kullanılmaktadır: etnografik, katılımcı araştırma ve ikincil kaynaklar.

Etnografik araştırmada mülakat, sessiz sorgulama, bağlamsal sorgulama ve kendini yerine koyma (kullanıcı haritası) yöntemleri uygulanmaktadır. Mülakatta karşıııkı konuşma varken sessiz sorgulamada ve bağlamsal sorgulamada ağırlıklı olarak gözleme dayanmaktadır. Ayrıca bağlamsal sorgulamada kişinin mekânında gözlem ve mülakat yapılmaktadır. Kullanıcı haritasında kullanıcıyla faaliyet beraberce adım adım gerçekleştirilmektedir.

Etnografik çalışma kişiyi kendi dünyası ve kurguladığı gerçeklik içinde anlamaya çalışan çoğulcu ve insani bir yaklaşımdır. Etnografi sosyal bilimlerde özellikle antropolojide kullanılan bir yöntemdir. İnsan kültürlerini inceleme de kullanılmaktadır. Etnografik çalışmalar farklı perspektiften bakmaktadırlar. Sadece kiş̧iyi değil kiş̧iyle temastaki tüm unsurları da gözlemlemektedirler. Kullanıcıların beklentileri ve dünyaya bakışı çözülmektedir. Empati insanları laboratuvar fareleri veya istatiksel olarak standart sapmanın ötesinde düşünme alışkanlığıdır. Yenilikçilik için insanların hayatları ilham vermeleri için ödünç alınmakta, onların yaşadıkları hayatta karşılaştıkları karmaşı olaylar için geliştirdikleri anlaşılmaz gibi görünen stratejileri de kavrama gayretinde olunmaktadır (Liedtka ve Ogilivie, 2011). Etnografik araştırmada mülakat, sessiz sorgulama, bağlamsal sorgulama ve müşteri haritası yöntemleri uygulanmaktadır. Müş̧eri haritasında mülakat ve gözlem yanında kişiyle beraber faaliyetler adım adım yapılmaktadır. Etnografik çalışması çıkarılmayan hiçbir projede inovasyon geliştirilememektedir (Lietka ve Ogilivie, 2011; Lietka vd., 2014).

Katılımcı araştırmasında kurgu oluşturulduktan sonra kullanıcıların bir faaliyeti gerçekleştirmesi beklenmektedir.

İkincil kaynaklar ise uzmanlar ve yazılı kaynaklardır. Uzmanlarla görüşme ve yazılı kaynaklar sektör hakkında ana hatların öğrenilmesine yaramaktadır.

Bu tekniklerdeki amaç konuyu her açıdan kuşatarak ve araştırmacıyı bir uzman haline getirerek gerçek sorunu ve çözüm alternatiflerini oluşturmaktır.

'Nedir bu?'yu anlamaya çalışmak varsayımları doğruluğunu kabul etmekten kaçınılmasını sağlamaktadır. Kullanıcılar hakkında sağlam ve derin içgörülerin bilgisini vermektedir. Doğrudan kullanıcılarla baştan iletişimde olmak yenilikçi fikrin başarısızlık riskini azaltmaktadır.

İkinci aşama anlamaktır (şekil 2). Birinci aşamada öğrenilenler yorumlanmaktadır (Luma Institute, 2012). Bu bölümde toplanılan veriler incelenmektedir. Genel eğilimleri ve içgörüleri gruplandırıyoruz. Toplanan bilgileri hepsini tek tek hafizamızda tutmak mümkün değildir. 
Gruplamalar yaparak kişiler bazında profil tiplemeleri, konular bazında ise kavramları (konseptleri) oluşturulmaktadır. Tiplemeler ve kavramlar üzerinden stratejiler belirlenmektedir. Beyin firtınasında "Peki ya” ile kışkırtıcı soruları sorarak mevcut statükoya karşı fikirler ve çözümler ortaya konmaktadır. Beyin firtınaları ancak empati aşamasını geçen donanımlı ekip üyeleriyle gerçekleşmektedir (Şekil 2). Sorunun kaynaklarını görme amacıyla sebep-sonuç analizleri yapılmaktadır. Alternatif çözümler aranmaktadır. Tasarım düşüncesinde ikinci aşama anlamak/beyin firtınasına geçiş artık yeni ilginç bir tecrübe ve bilgi öğrenilmediği noktada olmaktadır. Yapılan mülakatlar sıkıcı olmaya ve ilham vermemeye başlamaktadır. Birinci aşamada öğrenilenler beyin firtınasında yorumlanmaktadır. Peki ya sorusunda fikirler ve çözümler ortaya konmaktadır. Bu bölümde toplanılan veriler incelenmektedir. Genel eğilimleri ve iç görüleri gruplandırılmaktadır. Toplanan bilgileri hepsini tek tek hafızada tutmak mümkün değildir. Gruplamalar yaparak kişiler bazında profil tiplemeleri, konular bazında ise kavramlar oluşturulmaktadır. Profiller ve kavramlar üzerinden stratejiler belirlenmektedir.

Üçüncü aşama, yapmada, elle tutulabilir bir çözümün canlandırılmasıdır (Şekil 2). Çözümün anlaşılabilir ve değerlendirilebilir olması için kelimelerden ve hayallerden mümkün olduğunca kaçınıp bir prototip yapmak gerekmektedir (şekil 2). Prototipin kullanıcılar için anlaşılır olması ve görselleştirilmesi yeterlidir. Görsellik bir video, maket, senaryo veya eskiz olabilir. Önemli olan kullanıcının prototipi algılayabilmesi ve yorum yapabilmesidir. Çözümün anlaşılabilir ve değerlendirilebilir olması için kelimelerden ve hayallerden mümkün olduğunca kaçınıp, bir prototip koymak gerekmektedir. Prototipin kullanıcılar için anlaşılır olması ve görselleştirilmesi yeterlidir. Önemli olan kullanıcının algılayabilmesi ve yorum yapabilmesidir.

Prototipi kullanıcılara test ettirerek girişimci kendi dünyasının yansımalarını dayatmaz. Kendi doğrularıyla ilerlemez. Kullanıcı testinden geçinceye kadar sürekli deneme ve yanılma devam etmektedir. Amaç ilk primitif prototipten mükemmelliğe giden son ürüne ilerlemektir.

Dördüncü aşama, deneme-yanılmada prototipler kullanıcıların testine tabi tutulmaktadır (şekil 2). Test aşamasında kullanıcılar gördükleri veya dokundukları prototipler üzerinden yorum yapmaktadır. Kullanıcıların prototipler üzerindeki yorumları ışığında ürün son haline ulaşmaktadır. Bu sayede ürün piyasaya sağlam adımlarla çıkmakta, seri üretime ve satışa sürülmektedir.

Deneyin amacı hipotezi test etmektir (Ries 2013; Blank,2013). Tasarım düşüncesinde insanları ikna etme gayretinde olunmaz. İnsanlar dinlenir. Çözüm önerileri sunulur. Sunulan çözüm önerileri beğenilmezse başka çözüm önerileri getirilir. Eldeki hizmet satılmaya çalışılmamakta, kullanıcının ihtiyacına göre hizmet üretilmektedir.

Yalınlık kavramıla ürün bitmeden önce birçok kez deneme-yanılma sürecinden geçerek başarısızlığa karşı tedbir alınmaktadır (Ries, 2013) (Şekil 3). Girişimci olarak fikir üretmeye, hayal kurmaya, olması gerektiğini düşünmek yerine, kullanıcıya tanımakla zaman geçirilmelidir. Kullanıcı tecrübesi fikrin ve uygulamanın her aşamasında test edilmesini amaçlamaktadır. Hiçbir ressam tabloyu sıfırdan yapmamaktadır. Eskizini yapmakta, detaylandırmakta ve en sonunda resmetmektedir. Kullanıcılardan prototip ürünü kullanmaları istenmektedir. Deneme süresince sorular sorularak ya da kullanıcılardan sesli düşünmeleri istenerek yaşadıkları deneyimler gözlemlenmektedir. Sonra tekrar soru yöneltilerek yaşadıkları deneyimle ilgili daha derine inmek hedeflenmektedir. Denemeler görüntülü olarak kaydedilmekte ve tekrar tekrar izlenerek ürünün gerçek kullanıcılar tarafından kabul görüp görmeyeceği anlaşılmaya çalışılmaktadır. Kullanıcı testleri ürün piyasaya çıkmadan önce yapılırsa tesirlidir. Tasarım düşüncesinde amaç çözüme paydaşları da ortak etmektir. Çözümü uygulayacak kişilerin 
sürece ortak edilmesi kişilerin çözümü içselleştirmesini sağlamaktadır. Bundan dolayı çözüm paydaşlarla beraber kurgulanmaktadır (Blank, 2013).

Şekil 3: Yalınlık

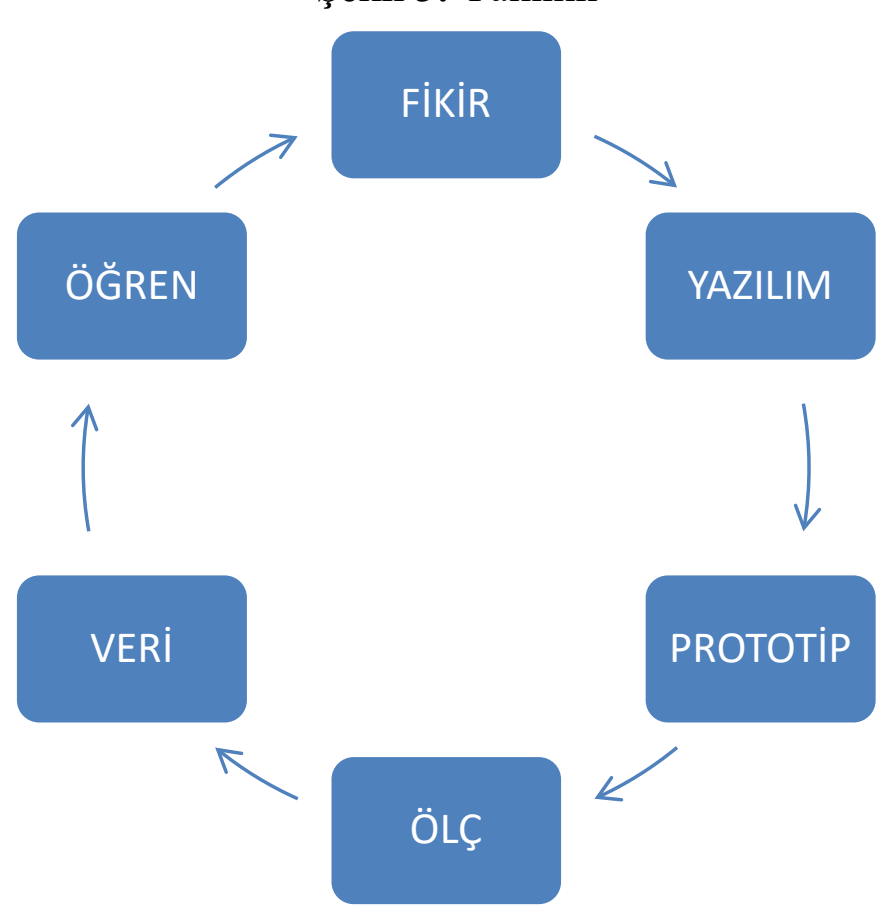

Kaynak: Ries, 2013.

Üçüncü bölümde tasarım düşüncesinin uygulamasında bir inovasyon projesi anlatılmaktadır. Metodolojinin 4 adımda nasıl uygulanıldığı gösterilmektedir. Sonuç bölümü takip etmektedir.

\section{Tasarım Düşüncesinin Uygulanışı}

$\mathrm{Bu}$ süreçte tasarım düşüncesinin görmek-anlamak-yapmak-test etmek metodu takip edilmektedir. Tasarım düşüncesi metodunu gerçek bir sorunda nasıl uygulanıldığı gösterilmektedir. Ele alınan sorun, İstanbul Büyükşehir Belediyesinde İGDAŞ’a bağlı kesin hesap birimindeki ciddi zaman ve maliyet kaybına yol açan ataşmanların yeniden tasarlanmasıdır. Sürecin sonucunda ataşman sayısı $\% 94$ oranında azaltılması başarıldı.

\subsection{Görmek}

İlk adım sorunun kök problemine inmektir. Konuyu derinlemesine araştırmak için paydaşlarla mülakatlar yapıldı. İlk önce görüşülecek kişilerin paydaş haritasını çıkartıldı.

Mülakat yapılan paydaşlar:

1. Birimde çalışanlar; 6 kişi

2. Altyapı yatırım yüklenicileri ve elemanları; 20 kişi 
3. Danışman firma elemanları; 4 firmadan 7 kişi

4. Hak edişi hazırlayan şantiye şeflikleri: 17 kişiyle (1 koordinatör, 4 şantiye şefliğinden 4 şef, 4 mühendis ve 3 teknisyen).

5. Aynı müdürlükteki diğer şefler ve elemanları (8 kişi -3 şef ve 5 çalışanı-).

6. Diğer birimlerdeki koordinatör, şef ve çalışanları.

Kendini yerine koyma ile bir hak ediş süreci birimle birlikte gözden geçirildi. Hak edişler incelendi. Günlük haritası çıkarıldı. Bir hak edişin gelmesinden hak edişi çıkardıkları zaman zarfindaki birimde çalışanların duygu değişimleri incelendi. En çok hangi noktalarda huzursuzluk yaşadıkları keşfedilmeye çalışıldı.

Ayrıca ortam sessizce gözlemlendi. Çalışanların muhataplarına karşı ve muhataplarında onlara karşı tutumları incelendi. Memnuniyetsizlik yaşadıkları konular not alındı.

\subsection{Anlamak}

Tüm bu görüşmelerden yaklaşık 100 çıkarım elde edildi. Tüm bu çıkarımlar 4 kavram altında gruplandı. Hak ediş incelenmesindeki süreçten 3 kavram belirdi. Hak edişle ilgisi olmayan çıarımlar ise "diğerleri" altında gruplandı.

1. Hak edişin hazırlanması

2. Hak edișin incelenmesi

3. Hak edişin bağlanması

4. Diğerleri

Yaratıcı matriks yöntemiyle beyin firtınasında birçok fikir ortaya çıktı (Tablo 1). Kavramlardaki problemlere karşı çözüm kaynakları olanların yerinde olunsaydı nasıl çözülürdü düşünülerek fikirler üretildi.

Tablo 1: Yaratıcı Matriks

\begin{tabular}{|l|l|l|l|}
\hline & Müdürlük & Hakediş Birimi & Yüklenici \\
\hline Hazırlama & & & \\
\hline İnceleme & & & \\
\hline Bağlanma & & & \\
\hline
\end{tabular}

Yöntem kaynağı: Luma Institute, 2014.

Yaratıcı matrikste ortaya çıkan tüm fikirler değerlendirilip, Önem/Kolaylık matriksine yerleştirildi (tablo 2). Hedef önemli ve kolay fikri hayata geçirmektir. 
Tablo 2: Önem/Kolaylık

\begin{tabular}{|l|l|l|}
\hline & Önem & Önemsiz \\
\hline Kolay & & \\
\hline Zor & & \\
\hline
\end{tabular}

Çalışanların incelerken ve yüklenicilerin hazırlarlarken çok fazla zaman alan, hata yapabilmeyi arttıran formların (ataşmanların) değiştirilmesine karar verildi.

\subsection{Yapmak}

Ataşmanlarda gereksiz bölümler silindi. Bazı bölümlerde hesap kurgusu yanlış planlamıştı, düzeltildi. Prototip olarak tüm sıkıntıları ortadan kaldıracak bir form (ataşman) üretildi.

\subsection{Test: Deneme-Yanılma}

Deneme-yanılmada prototipler paydaşların testine tabi tutuldu. Kullanıcılar prototipler üzerinden sesli eleştiriler yaptılar. Üretilen form prototipini paydaşlardan onay alınıncaya kadar 5 defa sil baştan tasarlandi.

\section{Elde Edilen Tasarruflar}

Elde edilen faydaları 4 kategoride incelenmektedir:

\section{A. Malzeme Tasarrufu}

Geçmişte çıkarılan hak edişleri bu yönteme göre incelendiğinde kâğıt, kartuş, printer, klasör ve diğer tüm malzemelerden \%94 tasarruf sağlandı. Bir hak ediş için 5142 a4 ataşman kâğıdı harcanırken bunu 394 a4 ataşman kâğıdına indirildi (tablo 3).

Tablo 3: Gerçekleşen bir hakedişten malzeme tasarrufu

\begin{tabular}{|c|c|c|c|}
\hline & Adet & Kazanç & Ne demek \\
\hline Toplam Ataşman Sayısı & 5.142 & \multirow{2}{*}{4.746} & \multirow{2}{*}{$\begin{array}{l}\text { Formun hiçbir maddi, bilgi ve veri } \\
\text { kaybı olmaksızın kayda geçmesi } \\
\text { sebebiyle ortadan kaldırılması }\end{array}$} \\
\hline $\begin{array}{l}\text { Yeni Uygulamada Toplam } \\
\text { Ataşman Sayıs1 }\end{array}$ & 396 & & \\
\hline Kaldırılan Ataşman Oranı & $94 \%$ & & \\
\hline
\end{tabular}




\section{B. Hak Ediş Hazırlama Tasarrufu}

Bir ataşmanın hazırlanması yaklaşık yarım dakika almaktadır. 4746 form için 2400 dakikalık (40 saatlik) tasarruf sağlanmaktadır. Bir iş günü 8 saat olduğunu düşünülürse 5 iş günü tasarruf edilmiştir.

\section{C. Şantiye Kontrol Zamanı Tasarrufu}

Şantiye kontrol için elde edilen tasarruf 660 dakika veya 11 saatlik tasarruf elde edilmektedir. Yine bir iş gününde 8 saatten toplamda 1,5 günlük iş yükü azaltıldı.

\section{Hak Ediş Kontrol Zamanı Tasarrufu}

Hak edişlerin kontrollünde azaltılan iş yükü 700 dakika veya 12 saat oldu. Yine iş günü hesabıyla 1,5 gün azalmaktadır.

Tüm iş günü tasarruflarını topladığımızda 5 gün (B maddesinden) $+1,5$ gün $(C)+1,5$ gün (D) 8 gün etmektedir. Hesap kesim birimimizde yılda 72 adet hak ediş yapıldığı düşünülürse toplamda 576 günlük $(72 * 8)$ iş günü kazancı ve ortalama olarak 4746 adet ataşmandan $341.712(72 * 4746)$ sayfalık tasarruf sağlanmaktadır. Ayrıca her hesap kesim için her 80-100 ataşman için 1 klasör harcanmaktadır. Bu 341.712 tasarruf edilen ataşman için yaklaşık 400 (341.712/90) klasöre denk gelmektedir.

\section{Sonuç}

Tasarım düşüncesi bir problem-çözüm sistemi olarak kullanıcı odaklı, inovasyon firsatlarını yakalamaya çalışan deneme-yanılma yöntemidir. 4 adımda yaratıcı çözüme ulaşılmaktadır: Görmek-Anlamak-Yapmak-Test Etmek. Tasarım düşüncesi sistemi insan odaklıdır. Kullanıcılarla empati kurulmaktadır. Görünür problemin altındaki gerçek problemin tanımlanması gerekmektedir. Etnografik metotlardan elde edilen çıkarımlar birbirleriyle benzeş olanlarla gruplamalar (sistemler) oluşturularak kavramlaştırılmakta ve çözümler (prototipler) üretilmektedir. Prototipler seri ve sık bir şekilde paydaşlara gösterilere geri bildirimler alınmaktadır.

Tasarım düşüncesi uygulamasına konu olan İGDAŞ'ın ödeme yapabilmesi için hesap kesim bölümünden onay alınmaktaydı. Kesin hesap bölümü ödeme iznini verebilmek için birçok form doldurmaktaydı. İş yükü bu ataşmanların (formların) şekli ve adedinden ortaya çıkmaktadır. Tasarım düşüncesi inovasyon sürecinde öncelikle tüm paydaşlarla görüşülüp, işlerini yaparlarken neler hissettikleri, düşündükleri, duydukları, yaptıkları, gördükleri soruldu. Sonunda ataşmanları radikal olarak sadeleştirerek ve gereksizleri tümden atarak, ataşman sayısı 5142'den 396'ya indirildi.

Yeni ataşman uygulamasının hak ediş incelemeye katkısı:

1. Birbirinin benzeri olan ataşmanlar elendi.

2. Ataşmanlar sadeleştirildi.

3. Malzeme israfının önüne geçildi.

4. Her bir ataşmanın hazırlanması ve kontrolü için ayrılan zamandan tasarruf sağlandı. 


\section{KAYNAKÇA}

Beverly, R. I. (2013). Design Thinking for Entrepreneurs and Small Businesses: Putting the Power of Design to Work, A press, New York.

Blank, S. (2013). "Why the Lean Start-Up Changes Everything”, Harvard Business Review, 4(2), 34-40.

Brown, T. (2008). “Design Thinking”, Harvard Business Review, 5(3), 56-65

Brown T. (2009). “Change by Design: How Design Thinking Transforms Organizations and Inspires Innovation”, Harper Business, New York.

Hulme, T. (2010). “12 Ways to Add Design Thinking Inti Your Project”, http://www.ted.com/ talks/emily_pilloton_teaching_design_for_change.html

Kelley, T. (2005). The Ten Faces of Innovation, Doubleday, New York.

Kelley, T. \& Kelley, D. (2014), Yaratıcı Özgüven, Optimist yayınları, İstanbul.

Klein, L. (2013). UX for Lean Startups: Faster, Smarter User Experience Research and Design Hardcover, O'Reilly Media, San Francisco.

Kumar, V. (2012). 101 Design Methods: A Structured Approach for Driving Innovation in Your Organization, Wiley, Chicago.

Liedtka J. \& Ogilvie, T. (2011). Designing for Growth, Columbia Business School, New York.

Liedtka, J. King, A. \& Bennett, K. (2014). Solvıng Problems With Design Thinking, Columbia Business School, New York.

Luma İnstitute (2012). Human Centred Design, Luma Institute, Philadelphia.

Luma Institute. (2014). “Innovation of Taxanomy”, Harvard Business Review, Jan/Feb.

Neumeier, M. (2009). The Designful Company, New Riders, New York.

Pink, D. (2006). A Whole New Mind, Riverhead Trade, New York.

Parsons, T. (2009). Thinking: Objects Contemporary Approaches to Product Design, AVA Publishing SA, London.

Pink, D. (2014). “Metaphor Marketing”, http://Www.Fastcompany.Com/33672/MetaphorMarketing.

Ries, E. (2011). Lean Startup, Crown Business, San Francisco.

Sara L. Beckman, C. \& Barry, M. (2013). “Innovation as a Learning Process: Embedding Design Thinking”, California Management Review, 50(1), 50-60.

Standford Design School (2009). d.school Bootcamp Bootleg, Standford Press, Standford.

Stanford Design School (2014). Design Thinking Virtual Crash Course.

http://www.youtube.com/watch?v=-FzFk3E5nxM 


\section{EXTENDED ABSTRACT}

\section{Design Thinking Application: The Form Revision in Public Administration}

The methodology of design thinking and its application to a public administration are analyzed.

This study is related to the development of the files that cause delays in the exact calculation unit of Istanbul Metropolitan Municipality Istanbul Gas Distribution Inc. (IGDAŞ) by design thinking method. In the current system, 5142 attachments are prepared per year for 72 files. This intensive workload caused the department members to be harsh when they are stressful to do their jobs, especially to the contractors. The number of attachments has been reduced from 5142 to 396 as a result of the implementation of the design thinking as innovation process. Our aim is to introduce this innovative system by solving this problem which affects work productivity and stress. In the process, we interviewed with our staff, managers, coordinators, contractors, engineers. Our remediation that we come up is to reorganize the forms. Thanks to this new solution, time and material saving reaches 576 days and 300,000 pages (94\% down).

In IGDAŞ, it is necessary to get approval from the account department in order to be able to make payments when contracting service is received. Many forms are filled in so that the final account section can also grant payment. These forms are called attachments. The workload is due to the shape and number of these attachments. The design thinking method is used in the solution of the problem in the Big City Municipality.

The design thinking is a trial-and-error method based on user focused and teamwork to capture innovation opportunities as a problem-solution system. Innovation in design thinking is a discipline rather than creativity. The design thinking follows a method connected with strict rules in demonstrating the solution.

The process is expressed in four stages: to see (what is?), to understand (what if?), to do (what wows?) and to test (what works?).

The first step is to see. We try to empathize with users. The stakeholder map is issued. Stakeholders are all persons and organizations that directly or indirectly affect the problem or solution. A list of the persons to be discussed is created on the stakeholder map. In this phase, situation, problem, subject, people, relations, goals, historical developments are investigated. All successful innovations begin with an accurate assessment of the issue. The focus of the research is on "users". The main philosophy of empathic knowledge is to understand the feelings of the other side. What is important in the methodology of design thinking is to find the right question rather than finding the right answer.

The second stage is to understand. The data collected in this section are analyzed. We group general trends and insights. It is not possible to keep the information collected in our individual memory. Grouping is done by making groupings and profile concepts are formed on the basis of subjects. Strategies are determined through concepts. In brainstorming, ideas and solutions are put forward against the current status quo by asking What if? with provocative questions. Brainstorming is carried out only with the team members who have passed the empathy stage. Alternative solutions are sought.

The third step is to revive a tangible solution in making. To make the solution understandable and evaluable, it is necessary to avoid the words and dreams as much as possible and shape a concrete prototype. It is sufficient for a basic prototype to be understood and visualized for the users. Visuality can be a video, model, scenario or sketch. What is important is that the user can detect and interpret the prototype.

The fourth step, by testing the prototype to the users, the entrepreneur does not impose the reflections of his own world. He doesn't progress with his own truth. Trial and error continue until the user approves the prototype. During the testing phase, users comment on the prototypes they see or touch. In the light of the user's comments on the prototypes, the product reaches its final state. The aim is to advance from the first primitive prototype to the perfect final product. 